Rev. Latinoam. Psicopat. Fund., São Paulo, v. 14, n. 3, p. 472-484, setembro 2011

\title{
ato na adolescência como resposta à inconsistência do Outro*
}

Pretende-se, pela articulação teórica de um caso clínico, analisar a incidência do ato e a referência frequente, nos discursos dos adolescentes, à influência das "más companhias". Para tal, utiliza-se a discussão ética de Lacan em seus Seminários dos anos 1959-1960 e 1968-1969. Conclui-se que o ato na adolescência é uma resposta possível ao que se mostra como inconsistência no Outro e visa, sob o modo da transgressão, atingir o que Lacan associa a das Ding freudiana. Indica-se, ainda, que tal resposta é reveladora do próprio desejo, o que estabelece uma direção para o trabalho clínico.

Palavras-chave: Adolescência, ética da psicanálise, Lacan, ato

* Artigo referente a resultado parcial de pesquisa realizada no Mestrado de Psicologia, Linha de Pesquisa de Psicologia Clínica, da Universidade Federal do Paraná (Curitiba, PR, Brasil). 
A partir de clínica desenvolvida com adolescentes em ambulatório infanto-juvenil de saúde mental, pretende-se discutir determinadas questões tendo por referência a psicanálise tomada desde uma dimensão ética. Para tanto parte-se de um recorte de caso clínico, do qual são destacadas as questões a serem discutidas com base no que Lacan trabalha no Seminário 7 - A ética da psicanálise (1959-1960) e no Seminário 16 - De um Outro ao outro (1968-1969), onde retoma a interrogação sobre a ética.

Trata-se de um adolescente de 15 anos com sérias dificuldades escolares, várias repetências, que está na quinta série há quatro anos. Quando chega ao ambulatório, foi expulso do colégio por ter jogado uma borracha no professor. Durante o tratamento fica evidente uma grande dificuldade em dar conta das atividades acadêmicas: sempre há reclamações dos professores, não para quieto, levanta-se várias vezes durante a aula. Com a professora do reforço mostra grandes dificuldades em terminar as tarefas. Ainda há queixas de comportamento, brigas com colegas, desrespeito a professores, depredação, falta às aulas e, por fim, coloca fogo numa lixeira.

Estas queixas são explicitadas pelo colégio e pelos pais. O adolescente sempre as nega, traz desculpas para o comportamento ou diz que foi o outro. Há uma grande dificuldade de se manter em um propósito valorizado socialmente, numa boa produção escolar, num bom comportamento e há estes atos que se inserem numa agitação motora, em atos antissociais, em brigas, em falta de respeito aos professores. A seguinte dinâmica se apresenta: depois que os pais são chamados à escola em razão de algum ato do adolescente, este se propõe a melhorar, diz que não fará mais isto, mantém-se num comportamento adequado, cumprindo as obrigações escolares até que, num determinado momento, irrompe um novo ato, assim se repetindo a dinâmica. 
Nota-se ainda uma dificuldade do adolescente em manter laços com seus pares, fica isolado, tem amigos esporádicos. Repete: “... antes só do que mal acompanhado". Sempre quando é acusado de algum destes atos no âmbito escolar, diz que não foi ele, foi outro adolescente que tem o mesmo nome que ele e é uma das "más companhias".

Prioriza-se neste relato dois pontos, os quais irão embasar a discussão proposta. Em primeiro lugar, os atos que o adolescente comete no âmbito escolar, que se caracterizam por uma ação impulsiva, irrefreável, disruptiva, quanto à qual o adolescente tem muito pouco a dizer. Mesmo quando narra a situação, o faz de modo pobre e incompleto, sendo marcado pela falta de palavras para designar os fatos. Em segundo lugar, a referência à influência das "más companhias", a qual se repete nos discursos dos adolescentes que, como este, são encaminhados para atendimento por comportamentos inadequados.

Para discutir estas questões, torna-se importante esclarecer qual conceito de adolescência embasa este trabalho. Toma-se a adolescência como um momento estruturante para o sujeito, na medida em que se refere à construção de um lugar no discurso social que inclua uma posição sexuada diante do Outro, o que acaba por conferir à adolescência um estatuto de operação psíquica. É o tempo em que o sujeito percebe que nunca encontrará na realidade o objeto adequado a uma satisfação total. $\mathrm{O}$ adolescente precisa se convencer da falta no Outro. Esta decepção remete o adolescente a procurar em outro espaço, que não o familiar, a reorganização de seu espaço psíquico e físico. $\mathrm{O}$ adolescente está à espera da designação de um lugar, de significantes que o representariam junto ao discurso social, por isso direciona-se para a rua. Vale dizer que é em relação ao laço social que a psicopatologia na adolescência encontra-se alocada na maioria das vezes.

Tem-se como orientação, portanto, os pontos acima indicados: a incidência do ato e a referência frequente, nos discursos dos adolescentes, à influência das "más companhias". A partir do entendimento da adolescência como operação psíquica e momento do sujeito se dar conta da inconsistência do Outro, abordar-se-á aqueles dois elementos evidenciados na clínica nos termos da discussão ética efetuada por Lacan no Seminário 7 - A ética da psicanálise e no Seminário 16 - De um Outro ao outro.

\section{O ato e sua implicação ética}

Iniciando pelo ato, pretende-se abordá-lo aqui não tanto de forma conceitual, ao modo de uma tentativa de explicação deste fenômeno na clínica, mas tomando-o como ponto de partida para pensar o manejo clínico destas situações no 
que elas remetem a um problema ético. Para tanto, remete-se ao início do Seminário 7, quando Lacan traz a novidade da obra de Freud e da experiência da psicanálise que dela decorre.

Assim, quando na história do conhecimento humano chega-se à noção de consciência, com o sujeito da ciência de Descartes, segue-se Freud, que diz não ser só consciência a dimensão psíquica do ser humano. Apresenta seu conceito de inconsciente como algo diferente da ideia de uma não consciência tão somente. $\mathrm{O}$ inconsciente freudiano rompe com o passado. O que ele estabelece sobre o que é inconsciente não tem por função preencher as lacunas da consciência, mas instaura no homem uma falta primeira de objetos que preencham e totalizem. Encontra-se aí, segundo Freud (1927), o pior dos golpes: o golpe psicológico no narcisismo humano, o de que o homem é determinado por algo que não conhece. A partir daí institui-se com a psicanálise o sujeito do inconsciente.

Esta descoberta de Freud pode ser resumida na frase Wo es war, soll Ich werden, que foi traduzida por Lacan (1959-1960) por "o Eu deve advir lá onde isso era". Assim o Eu, aí entendido como sujeito do inconsciente, que está para além do enunciado, mostra-se nos momentos de um corte no discurso. Na medida em que o discurso tropeça, interrompe-se, vem à tona um sujeito que perde toda unicidade, surgindo algo que fala do inconsciente. Trata-se do que está além do enunciado, do dito, do discurso consciente, no qual há uma vinculação da pessoa que fala a uma significação. Todo significante do sujeito da enunciação pode não estar presente no enunciado, sendo, portanto, uma cadeia que se inscreve em uma "outra cena", o inconsciente. Lacan (1959-1960, p. 17) localiza na frase de Freud a raiz da experiência moral na psicanálise, a entrada do paciente na análise, na qual o Eu se interroga sobre o que quer.

Coloca-se, então, para o psicanalista, a questão de como se orientar na resposta a este apelo. Para falar desta dimensão ética dada pela experiência psicanalítica e enraizada, segundo Freud, na dimensão do desejo inconsciente, Lacan retoma as concepções de ética desde Aristóteles ${ }^{1}$ e contrapõe a experiência psicanalítica a cada uma destas éticas.

Privilegia-se aqui a problematização da ética aristotélica realizada por Lacan, com o intuito de verificar o que propõe em torno da noção do bem, a qual orien-

1. Lacan traz, em seguida, a ética kantiana. Neste sistema ético a lei moral está em oposição ao prazer. Ele retira da moral qualquer elemento sentimental. Aproxima inusitadamente Kant de Sade, na medida em que, de forma subvertida, Sade traz a mesma coerência dos critérios kantianos, no que se destaca para justificar as posições do que se pode chamar de uma espécie de antimoral. Lacan ainda recorre à ética utilitarista, por meio da obra de Jeremy Bentham, em que o bem está a dispor do que é útil.

Rev. Latinoam. Psicopat. Fund., São Paulo, v. 14, n. 3, p. 472-484, setembro 2011 
tará a discussão mais adiante. Em relação a Aristóteles, recorre à oposição entre princípio do prazer e princípio de realidade. No nível do princípio do prazer, o que se apresenta ao sujeito como substância é o seu bem (Lacan, 1959-1960, p. 47). Numa relação de conflito com o princípio de prazer, tem-se o princípio de realidade, que para se satisfazer só pode alucinar a realidade. Assim, o objeto de satisfação não se encontra num objeto que corresponda ao representado, num reencontro. O fim da ação específica que visa à experiência de satisfação é reproduzir o estado inicial, reencontrar das Ding, o objeto perdido, cujo estatuto da perda Lacan põe aqui em causa. A cadeia significante, regulada pelo princípio do prazer, governa a busca do objeto, mas lhe impõe rodeios que conservam à distância das Ding, que se revela como ausente.

Das Ding é o que do real padece do significante (Lacan, 1959-1960, p. 149). Não há nada entre a organização da rede significante e a constituição no real do lugar central que é o campo de das Ding, há um vazio, o que indica que este campo é intransponível. Não há Bem Supremo visto que das Ding remete ao Outro primordial, a mãe, o próprio objeto do incesto. É um bem proibido e não há outro bem. O único bem possível é proibido, com o que Lacan (ibid., p. 90) entende que Freud inverte a lei moral. Assim, ao mesmo tempo que das Ding, no inconsciente, é o objeto perdido, é o que constitui a Lei. E, por isso, das Ding é o que se revela de mais íntimo e mais exterior, no que Lacan chama de "extimidade" (ibid., p. 173). Ao mesmo tempo que das Ding é fundada pela ordem simbólica, na operação de interdição, como objeto proibido, diz da própria constituição subjetiva. É aquilo que está mais distante, no campo do impossível; o que, no nível do inconsciente, só uma representação pode representar.

$\mathrm{O}$ bem resulta da composição significante que se encontra no inconsciente, com o que ela fornece de essencial, que é, ao mesmo tempo, a Spaltung, o corte no qual a divisão do sujeito se introduz (Lacan, 1959-1960, p. 128). Trata-se do lugar onde o sujeito não domina o que regula sua conduta, justamente pelo fato da cadeia significante contornar das Ding.

O que interessa registrar aqui é a referência de objeto perdido dada por das Ding remeter ao desejo, enquanto busca de um objeto desde sempre faltante. A ética, portanto, é a ligação da Lei com a estrutura do desejo, por meio da inscrição da Lei. O sujeito, como dividido, se constitui desejante, visto uma falta o estruturar. Assim, o que se busca na experiência analítica está para além da busca de prazer, que se liga à cadeia significante. Está no que permite definir o campo de das Ding como campo da ética, por remeter a esta falta estrutural, mas que determina o sujeito em sua divisão.

A ética da psicanálise é apresentada no Seminário 7 para além do bem, na medida em que a dimensão do bem levanta uma barreira na via do nosso desejo, 
como visto acima. Em relação às várias versões examinadas por Lacan na tradição do pensamento sobre a ética, verifica-se a dimensão de gozo que a questão do bem comporta. Desta forma, um repúdio radical de um certo ideal do bem é necessário para chegar a apreender a via que desenvolve a experiência analítica. (Lacan, 1959-1960, p. 280).

Para Lacan, no que se depreende do Seminário 7, uma transgressão é necessária para aceder ao gozo e, neste ponto, se articula com a Lei. A transgressão no sentido do gozo se apoia numa contradição. As vias para o gozo têm, nelas mesmas, algo que se amortece, que tende a ser impraticável, é a interdição que lhe serve de limite e veículo.

Se a via da análise não é a de um bem, ela nos leva em direção a das Ding, no que isso pode se articular ao mal e ao gozo implícito nas éticas tradicionais. Um gozo que não visa o bem, visa das Ding, naquilo que representa de transgressão da Lei. Este é o limite em que a prática psicanalítica se insere, já que o mal pode estar em das Ding (p. 156). Fica evidente que a ética da psicanálise não é a ética do bem-estar, o que o humano busca não necessariamente produz o bem do sujeito, mas pode produzir seu mal.

No entanto, Lacan (p. 254) afirma que esta transgressão tem relação com o que está em questão na interrogação ética, o sentido do desejo, que é diferente da necessidade. É em relação à estrutura dada por das Ding, de falta, de real, que o homem pode ser apreendido no campo do inconsciente, o que comporta uma Spaltung. E é em relação a esta divisão que se deve articular a função do desejo. O gozo se situa em direção a das Ding, mas também é graças a esta estrutura de falta que se funda o desejo como hiante. Desta forma, articula-se das Ding, desejo e gozo. Das Ding é a falta que move a estrutura, funda o desejo e inscreve um objeto proibido, desde sempre perdido, mas que o gozo visa se aproximar numa transgressão a esta proibição.

Neste momento do ensino de Lacan, o acesso ao gozo só é possível na transgressão da Lei. Posteriormente, no Seminário 16, com o conceito de objeto a como mais-de-gozar, Lacan elabora o acesso ao gozo como efeito de entropia, ${ }^{2}$ de desperdício, ao mesmo tempo que introduz um suplemento da perda de gozo. Desta forma, torna-se importante trazer esta contribuição de Lacan, de modo a permitir abordar a temática deste artigo, o ato na adolescência, num para além de uma transgressão à Lei.

A entrada do sujeito na linguagem acarreta uma perda originária de gozo. Esse gozo perdido, separado do corpo, desloca-se para o campo do Outro, e é

2. Entropia, palavra originária da termodinâmica, mede a parte da energia que não pode ser transformada em trabalho. 
nesse campo que o sujeito busca recuperar a parte perdida do corpo. No entanto, o objeto a como mais-de-gozar não preenche o campo do Outro, pois não é suficiente ao que se perde (Lacan, 1968-1969, p. 101). Nota-se que o efeito de perda é um efeito simbólico que se inscreve no vazio que se produz entre o corpo e seu gozo, na medida em que é a incidência do significante, ou da marca, que o determina. Portanto, há uma relação entre o efeito da perda, o objeto perdido, $a$, e o lugar do Outro, sem o qual ele não poderia se produzir. O gozo se institui por sua evacuação do campo do Outro, como lugar da fala.

A partir destas considerações teóricas, como pensar o ato do adolescente que é trazido para tratamento, com a demanda social, escolar, familiar, com a demanda de curar esta impulsividade, isto que remete a um gozo que não visa o bem, visa das Ding? Como curar das Ding? Sabe-se que o analista deve se precaver em relação a fazer o bem, ao desejo de curar, pois este pode desencaminhar qualquer possibilidade de análise. Lacan afirma então que "nosso desejo deve ser um não desejo de curar, para nos alertar das vias vulgares do bem, contra a falcatrua benéfica do querer-o-bem-do-sujeito" (Lacan, 1959-1960, p. 267).

Para Lacan (1968-1969, p. 202), o ato possui uma ênfase estrutural e é esta a única em que ele subsiste. Assim, o ato remete à estrutura naquilo que implica uma dimensão de satisfação pulsional, de gozo, dimensão esta que convoca das Ding, enquanto objeto perdido. Lacan propõe ainda o objeto $a$, como o que faz cócegas em das Ding. Trata-se do objeto a como mais-de-gozar, como perda de gozo dada pela interdição, dada pela linguagem, mas que visa a recuperação do gozo, ou seja, uma tentativa, sempre falha, de preencher a falta dada por das Ding.

Neste momento do ensino de Lacan, o mais-de-gozar, apesar de estar relacionado a das Ding, remeterá, diferente de sua posição no Seminário 7, a um para além da Lei. Rompe com o que poderia estar relacionado à Lei, seja numa ideia de normalização ou de transgressão. Adverte que, se uma análise propuser a normatização, o retorno à norma, o mais-de-gozar ficará de fora (p. 148). Nesta dimensão, o gozo é um absoluto, um real, como aquilo que sempre retorna ao mesmo lugar. Assim, se a dialética do prazer regula a cadeia significante, é num certo limite que está o campo do gozo, tudo o que implica a centralidade de uma zona proibida, pois nela o prazer é intenso demais.

$\mathrm{O}$ ato remete a esta dimensão de gozo absoluto, em que o sujeito não visa seu bem e sim sua satisfação e, acima de tudo, dar consistência ao Outro, recuperar o gozo perdido na operação de inscrição da marca simbólica dada pelo Outro. Desta forma, o problema ético aqui em jogo pode ser resumido na seguinte interrogação: como então tratar o ato em análise se ele fala de uma satisfação, de um ponto em que o sujeito está cativo numa resposta alienada à inconsistência do Outro, com relação à qual a adolescência designa um momento crucial? 


\section{As "más companhias" e a inconsistência do Outro}

O problema ético acima resumido remete, portanto, à inconsistência do $\mathrm{Ou}$ tro. Será por meio do que aparece nos discursos dos adolescentes, como a influência das "más companhias", que se pretende discutir esta questão. Recorre-se para tanto ao Seminário 7, no que Lacan articula sobre a morte de Deus. Para ele, o mito proposto por Freud em "Totem e tabu" (1913) do assassinato do Pai da horda, depois reforçado em "Moisés e o monoteísmo" (1939) pelo assassinato do Grande Homem, que precede o assassinato de Cristo, é o crime primitivo que funda a Lei primordial. Este assassinato não abre a via para o gozo que o pai interditava, mas reforça sua interdição. Mesmo com o obstáculo exterminado, o gozo não deixa de permanecer interditado. Aí se insere o Nome-do-Pai em sua função significante (Lacan, 1959-1960, p. 177).

A função da morte de Deus que o assassinato do pai representa é introduzida por Freud como um mito moderno (p. 178). O pai morto remete a que Deus está morto desde sempre. A normalização do desejo se dá do lado do Nome-do-Pai, na medida em que interdita um gozo proibido, fornecendo as vias ao desejo que estão relacionadas ao fato de Deus não existir, o que muda as bases do problema ético, já que o gozo, mesmo com o Pai morto, permanece proibido. Isto acaba por dar um estatuto ao Pai de personagem manco, fundando assim a inconsistência do Outro. A partir daí, a relação com a Lei adquire estranheza, já que a existência dessa Lei se situa e é fundada no Outro, $\mathrm{S}(\square)$, como a resposta derradeira à garantia pedida ao Outro. Se nada mais há senão a falta, o Outro se esvai, não há garantia.

Este $S(\square)$, significante do Outro barrado, ponto máximo da estrutura, será bastante explorado no Seminário 16 - De um Outro ao outro, por meio da inconsistência do Outro. Portanto, além do conceito de objeto a como mais-de-gozar, torna-se importante explorar as novas formas que Lacan se utiliza para falar desta inconsistência, visto que amplia a noção dada no Seminário 7 de Deus morto, argumentando a partir da lógica.

Neste sentido, o que ele faz no Seminário 16 é remeter ao paradoxo de Russell, em que nenhum conjunto pode ser ao mesmo tempo um conjunto e pertencer a si próprio. Propõe uma solução para este paradoxo: o conjunto de todos os conjuntos que não se contêm só pode ser inscrito por meio da formulação $\mathrm{E}$ (x\x) (Lacan, 1968-1969, p. 302). Se x é diferente de x, um significante não pode designar a si mesmo, o que remete sempre a outro significante. Ao designar o Outro por A, o A não pode se designar como A e estar contido em A, só pode remeter a Outro. O primeiro Outro que há é radicalmente Outro. O Outro em sua inscrição é separado dessa própria inscrição.

Rev. Latinoam. Psicopat. Fund., São Paulo, v. 14, n. 3, p. 472-484, setembro 2011 
O matema $\mathrm{S}(\square)$ é a expressão desta contradição como o significante do Outro que não está no Outro. Na medida em que o Nome-do-Pai é o significante do Outro enquanto lugar da Lei, não há uma duplicação do Outro (A), uma vez que o Outro como conjunto de significantes não comportaria seu próprio significante.

Desta forma, o Outro não pode ser concebido como um código fechado, no qual o discurso se instituiria sem falhas e seria totalizante (Lacan, 1968-1969, p. 57). O A tem em si a falha, decorrente de não podermos saber o que ele contém. O lugar do Outro não encontra garantia, sendo um lugar vazado. Será justamente o objeto a o furo que se designa no nível do Outro, quando ele é questionado em sua relação com o sujeito.

Esta inconsistência do Outro, que foi melhor formalizada no Seminário 16, já está no Seminário 7, quando Lacan aproxima a morte de Deus do $\mathrm{S}(\square)$ para remetê-los ao mandamento: "Amar ao próximo como a ti mesmo", como articulado por Freud (1930) no "Mal-estar na civilização". O amor ao próximo seria a via em que se perde o acesso ao gozo (Lacan, 1959-1960, p. 227). Este amor surge da falta de consistência do Outro para tamponar a maldade profunda que habita o próximo e a mim. Assim, o meu gozo, quando o próximo surge com sua agressividade, recua e retorna contra mim, o que me impede de transpor uma certa fronteira no limite de das Ding. Este próximo, com seu gozo nocivo, maligno, se propõe como problema para o amor. Desta forma, o mal-estar articulado por Freud se dá porque o gozo é um mal, porque comporta o mal do próximo. O bem do amor ao próximo nos mantém afastado do gozo, assim se recua diante da traição de meu próximo e, por trás de meu semelhante, renuncio a meu próprio gozo.

O mandamento de amor ao próximo, ao mesmo tempo que barra o meu acesso ao gozo e o do próximo, coloca em evidência esta possibilidade; se não houvesse, no limite, a mediação da Lei. Diante da garantia que falta, recuo diante do gozo, o que se tampona com o amor ao próximo (p. 237).

Mais uma vez recorre-se ao Seminário 16 para melhor delimitar o estatuto deste próximo. Lacan retoma a introdução que Freud faz de das Ding por meio da função do nebenmesch, do próximo, do que é mais próximo do homem, mas muito ambíguo. Esse próximo é uma exterioridade que se identifica com algo que me é o mais íntimo, é justamente aquilo que sou obrigado a reconhecer do lado de fora, o êxtimo que conjuga o íntimo com a exterioridade radical. Porém, este próximo não é o Outro. O próximo é a iminência intolerável do gozo e o Outro é o lugar do qual se limpou o gozo, já que é no Outro que está o inconsciente estruturado como uma linguagem (Lacan, 1968-1969, p. 219).

Diante da inconsistência do Outro, tem-se como alternativa amar ao próximo, para não se dar conta do mal que habita o próximo e o próprio sujeito. $\mathrm{Na}$ adolescência, momento de se deparar com a falta de consistência do Outro, este 
próximo que poderia dar acesso à via do bem é a "má companhia". Fica evidente que ele é habitado por um gozo nocivo, que está para além do amor ao próximo. Esta "má companhia" encarna a própria exterioridade do gozo e coloca num para além do sujeito aquilo que lhe é mais interior. Frente à impossibilidade do que se coloca no lugar do ideal do eu fazer o bem, algo enigmático se propõe e retorna sem cessar na sua ação, com a ameaça de consequências desconhecidas. Mais uma vez o ato, como uma ação que visa das Ding, no que tem de bem e de mal, surge como gozo.

\section{Uma direção para o trabalho clínico}

Conjugou-se, portanto, os dois pontos da discussão proposta - a incidência do ato na adolescência e a referência à influência das "más companhias" - com os elementos teóricos: o direcionamento ético que a psicanálise propõe, a inconsistência do Outro, o gozo tanto como transgressão da Lei que visa das Ding, como na sua vertente de mais-de-gozar. Pode-se pensar, assim, que o ato na adolescência é uma resposta possível ao que se mostra como inconsistência no Outro. Pela impossibilidade de tamponar esta falta pela via do amor, visto o adolescente se dar conta que o próximo tem um gozo nocivo, gozo que fala do seu próprio, e em razão de uma impossibilidade de limpar este gozo pela via simbólica, a via do ato se abre, em um modo de satisfação que visa das Ding, numa transgressão. Desta forma, o ponto importante a considerar do gozo enquanto transgressão é que, por mais que o ideal do homem seja fazer o bem e se encontrar conforme a uma norma, no horizonte de seu próprio bem, o sujeito revela o mistério do seu desejo (Lacan, 1959-1960, p. 288). Isto porque, na via de seu desejo, há algo de irredutível que se dirige e se funda em das Ding, no que isto remete à transgressão da Lei. Das Ding revela a transgressão, mas também o desejo em sua irredutibilidade.

Para dar conta deste impasse do gozo enquanto transgressão, mas que revela um desejo, o conceito de objeto a, como mais-de-gozar, como entropia, dará lugar a uma nova perspectiva em que a ação como um ato estrutural visa à satisfação, num gozo absoluto que busca completar uma perda dada pela introdução do sujeito na linguagem. Nesta perspectiva, o ato como sendo do campo do gozo não é mais transgressão, é da ordem da estrutura e, como tal, deve ser tomado por falar da falta e de uma tentativa de recuperação de algo perdido e, portanto, remeter à verdade do sujeito. Assim, como dado da estrutura, o ato, indica Lacan, é fracasso. Para sustentar tal afirmação, remete ao que a psicanálise mostrou desde sempre em relação ao ato falho (Lacan, 1968-1969, p. 334). É neste 
ponto que se coloca a direção da análise e sua orientação ética, pois, como fracassa, fala de uma verdade e é esta verdade que deve ser evidenciada.

$\mathrm{O}$ objeto $a$, que além de ser mais-de-gozar é causa de desejo, introduz a divisão do sujeito, mas é essencialmente falta. A interpretação analítica visa essa divisão do sujeito, o $a$, para ter como efeito a verdade, que está do lado do desejo. Mais precisamente visa das Ding e o objeto a como causa substitutiva do que constitui a falha do sujeito. No entanto, desta verdade o sujeito é incurável, pois ela é a própria estrutura.

Para finalizar, retoma-se o recorte de caso clínico acima relatado, frente aos impasses da adolescência, às dificuldades de se situar no discurso social. O adolescente se vê impelido a buscar fora do âmbito familiar os laços identificatórios e o próximo a ser amado. No entanto, este próximo é aquele que evidencia o gozo nocivo que o habita. Como não há possibilidade de se situar frente a isto, pela via do simbólico, surgem os atos, o mau comportamento. Este é desculpado pela influência destas "más companhias", o gozo está do lado de fora. Será quando o adolescente puder se apropriar deste ato como seu - "Eu não sei o que acontece comigo, quando vi já fiz" - que algo da ordem do fracasso colocará em evidência um enigma. Um enigma que incita ao saber e deve conduzi-lo à verdade, uma verdade incurável, a falta. Tem-se, assim, uma direção clínica que escapa à alternativa entre ter no horizonte a normalização demandada quando o ato é tornado signo de um transtorno ou meramente sancioná-lo enquanto transgressão. Esta direção permite escutar, para além do transtorno, algo que implica aquele que fala num mal-estar, que está para além do mal causado no social, mas fala da falta e daquilo que esta falta mobiliza de resposta possível para cada sujeito.

\section{Referências}

Freud, S. (1913). Totem e tabu. Trad. Jayme Salomão. In: Edição Standard Brasileira das Obras Psicológicas Completas de Sigmund Freud. Rio de Janeiro: Imago, 1980. V. 13.

. (1927). O futuro de uma Ilusão. Trad. Jayme Salomão. In: Edição Standard Brasileira das Obras Psicológicas Completas de Sigmund Freud. Rio de Janeiro: Imago, 1980. V. 21.

. (1930). Mal-estar da civilização. Trad. Jayme Salomão. In: Edição Standard Brasileira das Obras Psicológicas Completas de Sigmund Freud. Rio de Janeiro: Imago, 1980. V. 18.

. (1939). Moisés e o monoteísmo. Trad. Jayme Salomão. In: Edição Standard

Rev. Latinoam. Psicopat. Fund., São Paulo, v. 14, n. 3, p. 472-484, setembro 2011 
Brasileira das Obras Psicológicas Completas de Sigmund Freud. Rio de Janeiro: Imago, 1980. V. 23.

Lacan, J. (1959-1960). O seminário. Livro 7. A ética da psicanálise. Rio de Janeiro: Jorge Zahar, 1997.

. (1968-1969). O seminário. Livro 16. De um Outro ao outro. Rio de Janeiro:

Jorge Zahar, 2008.

\section{Resumos}

(A teenager's act as a reactive response to inconsistency in the Other)

In this article the author uses the theoretical articulation of a clinical case to analyze the impact of the act and the frequent reference, in teenage discourse, of the influence of "bad company." Lacan's discussion on ethics in his Seminars from 19591960 and 1968-1969 are referred to in the process. The author concludes that the act in adolescence is a possible response to what are seen as inconsistencies in the Other, and it aims, through transgression, to reach what Lacan associates with Freud's das Ding. This response is also indicative of desire itself, which sets a direction for clinical work.

Key words: Teenager, ethics of psychoanalysis, Lacan, act

(L'acte chez l'adolescent comme réponse face à l'inconsistance de l'Autre)

On envisage dans cet article, à travers l'articulation théorique d'un cas clinique, analyser l'incidence de l'acte et la référence courante, dans le discours des adolescents, à l'influence de la 'mauvaise compagnie'. Pour y parvenir, on fait usage de la discussion éthique des Séminaires de Lacan des années 1959-1960 et 1968-1969. On conclut que l'acte chez l'adolescent est une réponse possible à ce qui se présente comme inconsistance chez l'Autre et qui envisage, en tant que transgression, atteindre la dimension que Lacan relie au concept de 'das Ding' chez Freud. On indique que ladite réponse révèle le désir lui-même, ce qui établit une direction pour le travail clinique.

Mots clés: Adolescence, éthique de la psychanalyse, Lacan, acte

(El acto en la adolescencia como una respuesta frente a la inconsistencia del Otro)

Se objetiva, por medio de la articulación teórica de un caso clínico, analizar el impacto del acto y la referencia frecuente en el discurso de los adolescentes, a la influencia de las "malas compañías". Con este objetivo, utilizamos la discusión ética de Lacan que consta en sus Seminarios de los años 1959-1960 y 1968-1969. Concluimos que el acto en la adolescencia es una respuesta posible a lo que se muestra 
como inconsistencia en el Otro, y que busca, a través de la transgresión, llegar a lo que Lacan asocia al das Ding freudiano. Además, esta respuesta revela el propio deseo, indicando así un curso para el trabajo clínico.

Palabras clave: Adolescencia, la ética del psicoanálisis, Lacan, acto

Citação/Citation: Stenzel, M.; DARRIBA, V.A. O ato na adolescência como resposta frente à inconsistência do Outro. Revista Latinoamericana de Psicopatologia Fundamental, São Paulo, v. 14 , n. 3, p. 472-485, set.2011.

Editor do artigo/Editor: Prof. Dr. Manoel Tosta Berlinck

Recebido/Received: 20.8.2010/ 8.20.2010 Aceito/Accepted: 18.11.2010/11.18.2010

Copyright: ( $) 2009$ Associação Universitária de Pesquisa em Psicopatologia Fundamental/ University Association for Research in Fundamental Psychopathology. Este é um artigo de livre acesso, que permite uso irrestrito, distribuição e reprodução em qualquer meio, desde que $\mathrm{o}$ autor e a fonte sejam citados/This is an open-access article, which permits unrestricted use, distribution, and reproduction in any medium, provided the original author and source are credited.

Financiamento/Funding: Os autores declaram não ter sido financiados ou apoiados/The authors have no support or funding to report.

Conflito de interesses/Conflict of interest: Os autores declaram que não há conflito de interesses/The authors declare that has no conflict of interest.

\section{Mirela STENZeL}

Psicóloga; Mestranda em Psicologia na Linha de Psicologia Clínica da Universidade Federal do Paraná - UFPR (Curitiba, PR, Br); Participante do Laboratório de Psicanálise da Universidade Federal do Paraná - UFPR (Curitiba, PR, Br).

Rua Capitão Souza Franco, 945/32 - Bigorrilho

80730-420 Curitiba, PR, Brasil

Fone: (41) 3336-6358 / 9942-0100.

e-mail: mirstenzel@hotmail.com

\section{Vinicius AnCiães Darriba}

Professor do Programa de Mestrado em Psicologia da Universidade Federal do Paraná UFPR (Curitiba, PR, Br); Vice-coordenador do Laboratório de Psicanálise da Universidade Federal do Paraná - UFPR (Curitiba, PR, Br).

Praça Santos Andrade, 50 - Prédio Histórico, $1^{\circ}$ andar, sala 115 - Centro 80060-000 Curitiba, PR, Br

Fone: (41) 3310-2625

e-mail:vdarriba@ufpr.br 